\title{
Regra Prática Para a Limitação das Repetições nas Medidas Físico-Químicas ${ }^{\natural}$
}

\author{
Arthur O. Schwab \\ Instituto de Biologia e Pesquisas Tecnológicas
}

\begin{abstract}
In order to obtain a limitation of the number of repetitions in physico-chemical measurements, the author proposes formula 8 of this paper. $\Delta$ is the difference between the maximum and minimum value of the measurements (form. 3 ) and $A$ the approximation desired or imposed.
\end{abstract}

Key Words: Physico-chemical measurements

\section{INTRODUÇÃO}

Toda medida físico-química, efetuada em condições adequadas, está inevitavelmente sujeita a pequenas flutuações de caráter fortuito ("erros acidentais") e que ora lhe aumentam, ora lhe diminuem o resultado. $\mathrm{O}$ experimentador costuma pôr-se ao abrigo dessas flutuações, repetindo a medida grande número de vezes e admitindo como certa, ou mais plausível, a média aritmética de todos os resultados. Teoricamente, quando o número de repetições atingir valor infinito, a média obtida representará o valor exato da grandeza a determinar, - supondo excluído todo erro sistemático.

A regra prática, assim formulada, parece simples, lógica e suficiente. Não obstante, ela encerra grave indeterminação no que tange ao número de repetições, pois este, na prática, nunca é elevado. É evidente, óbvio mesmo, que os diversos métodos usados no laboratório não são equivalentes, não são igualmente precisos. Uns exigem menor, outros maior número de repetições, mas, até agora, nenhuma regra prática foi estabelecida para calcular o número mais adequado a cada processo. Tal número é absolutamente arbitrário e fixado apenas pelo bom senso do experimentador.

Diante desta indeterminação, a clássica "teoria dos erros" recomenda repetir a medida um número de vezes maior possível e aplicar à série de resultados cálculos estatísticos previamente postulados e que tem por fim avaliar a "precisão" da série, isto é, o "erro" com que se deve contar no resultado global. Para este fim, preconiza o cálculo do "erro médio", "erro provável", "erro da média", etc. O erro médio de cada medida,

$$
\delta=\sqrt{\frac{\sum e^{2}}{n}}=\text { const } .
$$

dado o seu caráter de média, é independente do número de repetições e, do ponto de vista estatístico, representa um "parâmetro" característico da série. Mede sua "precisão" ou "dispersão" e está relacionado com o módulo de

\footnotetext{
$\wp$ Artigo publicado no Arquivos de Biologia e Tecnologia, v. 2, pp. 33-40, 1947.
} 
convergência ou constante $h$ da lei de Gauss pela expressão

$$
\delta=\frac{1}{h \sqrt{2}}
$$

Nota - Para simplificar os cálculos, o erro "e" da fórmula acima representa o "erro verdadeiro", que, na prática, é substituído pelo "erro aparente", determinável apenas com $n-1$ graus de liberdade. Por este motivo, encontra-se geralmente $n$ substituído por $n-1$.

$\mathrm{O}$ "erro da média"

$$
\mu=\sqrt{\frac{\sum e^{2}}{n^{2}}}
$$

evidentemente é função de $n$; diminui, quando $n$ aumenta e anula-se quando $n=\infty$, isto é, neste limite, a média coincide com o valor exato da grandeza a avaliar.

Das duas definições citadas deduzimos:

$$
\begin{aligned}
& \mathrm{n} \delta^{2}=\sum^{n} e^{2} \\
& \mathrm{n}^{2} \mu^{2}=\sum^{n} e^{2}
\end{aligned}
$$

Para limitar o número $n$ de repetições, partimos dos seguintes fatos de observação banal, quotidiana:

$1^{\circ}$ Numa série suficientemente longa de medições observamos, desde o início, uma medida máxima, $M x$, e outra mínima, $M n$, só excepcionalmente ultrapassadas: a série se "estabiliza" prontamente.

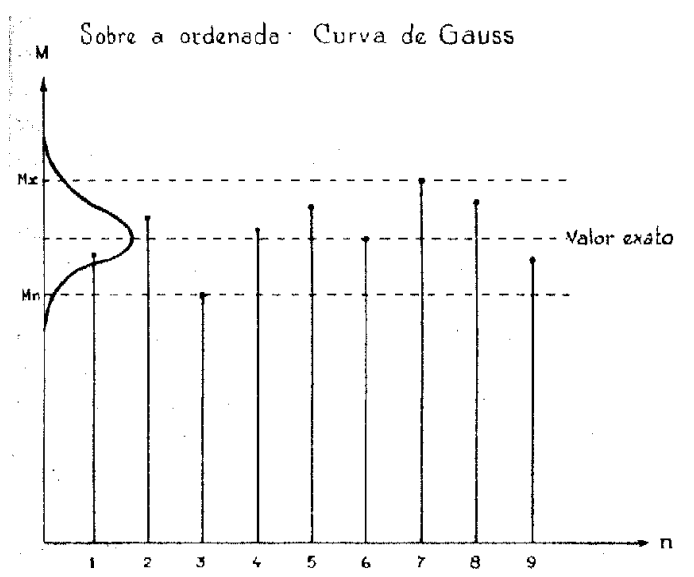

Fig. 1
Como bem o ilustra o gráfico da figura $n^{\circ} 1$, a diferença

$$
\Delta=M x-M n=\text { const } .
$$

atinge rapidamente valor máximo, constante, e que, por isso, é independente do número total de repetições, isto é, como $\delta$, pode servir como medida da "precisão" ou "dispersão" da série. Este fato aparentemente contradiz a lei de Gauss, que admite erros de qualquer grandeza, mas atribui-lhes probabilidade (frequiência) tão pequena que, praticamente, são inexistentes. Além disso, a lei em apreço só se aplica a séries muito extensas, nunca observadas nos trabalhos de laboratório.

$2^{\circ}$ A sensibilidade dos nossos instrumentos ou métodos não é infinita. Toda medida de grandeza convenientemente definida é feita com certa aproximação $A$, diretamente relacionada com as causas das flutuações fortuitas (erros acidentais) e que, na melhor das hipóteses, é igual à sensibilidade do instrumento ou método. Assim, por exemplo, não é possível medir frações de milímetro com escala graduada em milímetros, nem é possível pesar centésimos de miligrama com balança sensível ao décimo de miligrama, por maior que seja o número de repetições.

Em virtude da existência dessa aproximação $A$, desejada (nos casos de limitação voluntária a certa aproximação previamente estabelecida) ou imposta pelas condições experimentais, todo número de repetições superior a certo limite " $m$ " resulta em pura perda de tempo e trabalho. Em outras palavras, o número de repetições é necessariamente limitado a esse valor $m$. Deduz-se ainda que o erro da média, $\mu$ não pode ser inferior a certo limite, função de $m$, o que nos permite definir imediatamente o que se pode chamar média boa ou razoável.

Estabelecemos, baseados nas considerações anteriores, que a média é "boa", "razoável" ou "adequada", quando seu erro (erro da média), $\mu$, é igual à aproximação $A$, desejada ou imposta. Formulamos, pois:

$$
\mu=A
$$

e perguntamos: quantas vezes devemos repetir a medida para obter este resultado?

Sabemos que o erro da média é função de $n$ e o gráfico da figura $\mathrm{n}^{\circ} 2$ nos mostra de que maneira $\mu$ diminui quando $n$ aumenta. Para certo valor $\mu=A$, 
obtemos $n=m$ e o problema se reduz a esta pergunta: qual é o valor de $m$ ?

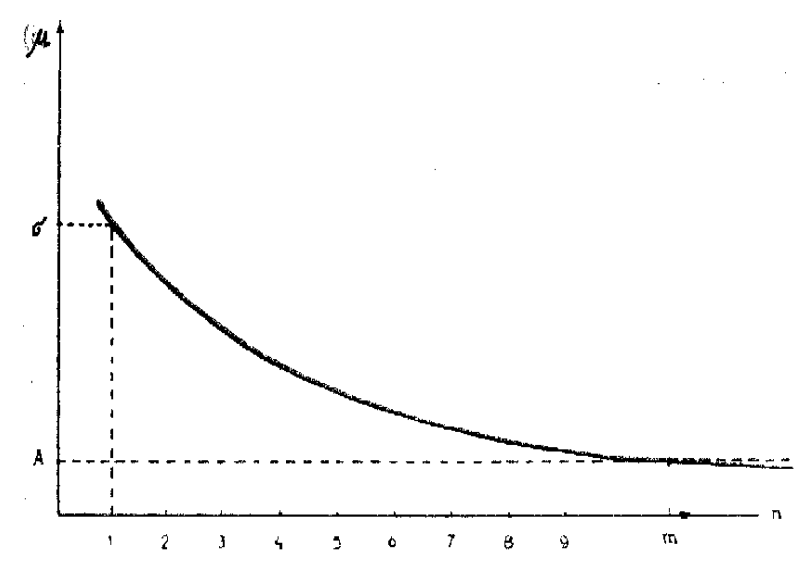

Fig. 2

Para achar resposta, partimos da relação (3). É evidente, e o gráfico $\mathrm{n}^{\circ} 1$ demonstra, que o valor absoluto de qualquer erro de uma série de medidas é inferior à diferença máxima $\Delta$. Portanto

$$
|e|<\Delta
$$

\section{Logo}

$$
e^{2}<\Delta^{2}
$$

$$
\begin{aligned}
& \sum^{n} e^{2}<n \Delta^{2} \\
& \sum^{m} e^{2}<m \Delta^{2}
\end{aligned}
$$

Mas, segundo (2) e (4)

$$
\sum^{m} e^{2}<m^{2} A^{2}
$$

$$
\begin{array}{ll}
\text { Portanto } & m<\frac{\Delta^{2}}{A^{2}}, \\
\text { ou então } & m=g \frac{\Delta^{2}}{A^{2}},
\end{array}
$$

com $g<1$.

Trata-se agora de precisar melhor o valor de $g$. De (1) e (5) deduzimos imediatamente

$$
m<\frac{o^{2}}{\Delta^{2}}
$$

Igualamos com (6), obtemos

$$
g<\frac{o^{2}}{\Delta^{2}}
$$

Ora, $\delta$ e $\Delta$ possuem ambos o caráter de parâmetros, isto é, são independentes do número total de medidas. Ambos servem para medir a precisão ou dispersão da série e, por isso, devem variar paralelamente de uma série para outra, e independentemente da natureza da medida (mecânica, elétrica, óptica, biológica, etc.). Em outras palavras: $g$ possui o caráter de uma constante "universal". A teoria clássica dos erros desconhece a existência de erros máximos ou mínimos e por isso pensamos ser impossível calcular teoricamente o valor de $g$. Resta-nos apenas o recurso de determiná-lo empiricamente a partir da relação (7).

Baseados em nossa experiência, aliás, deficientíssima, admitimos provisoriamente $\mathrm{o}$ valor $g=1 / 10$. A fórmula (6) toma o aspecto

$$
m=1 / 10 \frac{\Delta^{2}}{A^{2}}
$$

É interessante comparar os valores de $m$, assim calculados, com os da relação $\Delta / A$, como é feito a seguir:

$$
\begin{array}{ll}
\text { Relação }=5 & m=2,5 \\
\text { Relação }=10 & m=10 \\
\text { Relação }=15 & m=22,5 \\
\text { Relação }=20 & m=40 \\
\text { Relação }=30 & m=90 \\
\text { Relação }=40 & m=160
\end{array}
$$

etc.

Da tabela acima tiramos a seguinte conclusão, perfeitamente lógica: É bem mais econômico caprichar nas medidas, isto é, reduzir o valor de $\Delta$, do que pretender obter a mesma precisão no resultado final multiplicando o número de repetições. Esta conclusão constitui a essência e a principal vantagem da regra aqui proposta, aplicável a todos os trabalhos de rotina e especialmente nas práticas dos laboratórios de ensino. O operador, ou aluno, que trabalha sem os devidos cuidados, é automaticamente obrigado a multiplicar o número de medições, garantindo assim resultados de precisão constante. 
O seguinte exemplo ilustra a aplicação da regra na prática. - Fazemos primeiramente 10 medidas e constatamos que $\Delta A$ é igual a 12 . Aumentamos para 15 o número de repetições. Nesta nova série $\Delta / A$ aumentou para 16. Com 20 medições, verificamos que $\Delta / A$ conserva seu valor. A série é então considerada suficiente e sua média pode ser calculada. $\mathrm{O}$ erro desta média será fatalmente igual ou inferior à aproximação desejada ou imposta.

$\mathrm{O}$ resultado final, média das medições deve ser escrito de tal forma que todas as cifras, menos a última, sejam exatas. Esta última tem caráter puramente simbólico: ela nos indica com que aproximação foi feita a medida. Trabalhando segundo o método aqui exposto, sabemos de antemão que todas as cifras da média são exatas até a aproximação $A$, convenientemente representada por fração decimal $(0,1-0,01-$ 0,001 , etc.) da unidade adotada. Por exemplo, seja $A=0,1$ e 33,4622 a média da série; escreveremos o resultado sob a forma " 33,46 ", com todas as cifras exatas, menos a última.

Finalizando, advertimos que as relações aqui expostas são essencialmente estatísticas. Aplicamse com maior ou menor rigor apenas a séries longas. Contudo, pensamos que tal fato não lhes diminui o valor prático. 